\title{
Contribuições da Educação Matemática para a cultura de respeito à dignidade humana
}

\section{- Contributions of Mathematics Education to the culture of respect for human dignity}

Lygianne Batista Vieira'

Geraldo Eustáquio Moreira²

Resumo: Este texto tem o propósito de apresentar as contribuições da Educação Matemática no desafio de construir uma cultura de respeito à dignidade humana, excepcionalmente, em tempo de pandemia e, permanentemente, no pós-pandemia. Utilizamos as produções de Ubiratan D'Ambrosio, de Ole Skovsmose e de Eric Gutstein com o argumento de que a Educação Matemática também deve se responsabilizar pela formação sociopolítica dos estudantes. Para tanto, iniciamos o texto, discorrendo sobre a concepção de dignidade humana como construção intersubjetiva, tendo como principal interlocutor Boaventura de Sousa Santos. Em nossa reflexão, enfatizamos que a falta de consciência sociopolítica dos direitos, bem como, de dignidade humana, resulta na banalização das situações de injustiças e de opressões vividas pela sociedade brasileira. E que as desigualdades sociais são problemas que impedem o enfrentamento da Covid-19. Na busca do lugar de fala da Educação Matemática diante deste cenário, reforçamos o Triângulo Primordial de Ubiratan D'Ambrosio compreendido como: um indivíduo, um outro indivíduo e, portanto, a sociedade, e a natureza como possibilidade filosófica e metodológica de atuação. Aliado a isso, o

1 Doutora em Educação (UnB). Professora substituta da Faculdade de Educação - Universidade de Brasília (UnB), Brasília, DF, Brasil. Vice-Líder do Grupo de Pesquisa CNPq: Dzeta Investigações em Educação Matemática DIEM. E-mail: lygivieira@gmail.com

2 Pós-Doutor em Educação (UERJ); Doutor em Educação Matemática (PUC-SP). Professor Adjunto da UnB. Pesquisador do Programa de Pós-Graduação em Educação - PPGE/UnB. Brasília, DF, Brasil. Líder do Grupo de Pesquisa CNPq: Dzeta Investigações em Educação Matemática - DIEM. E-mail: geust2007@gmail.com. 
poder de formatação da sociedade de Skovsmose e o "ler" e "escrever" o mundo de Gutstein representam uma forma de inserção da matemática no desafio de construir uma sociedade que respeita a dignidade humana. Ciente deste papel, é preciso que a Educação Matemática reconheça seu potencial transformador primando pela formação de jovens amparada pelos princípios da humanização, da sustentabilidade e da paz.

Palavras-chave: Educação Matemática. Dignidade humana. Pandemia. Pós-pandemia. Formação sociopolítica.

\begin{abstract}
This text aims to present the contributions of Mathematics Education in the challenge of building a culture of respect for human dignity, exceptionally, in a time of pandemic and, permanently, in the post-pandemic. We use the productions of Ubiratan D'Ambrosio, Ole Skovsmose and Eric Gutstein with the argument that Mathematics Education should also be responsible for the socio-political formation of students. To this end, we begin the text, discussing the conception of human dignity as an intersubjective construction, having as main interlocutor Boa Ventura de Sousa Santos. In our reflection, we emphasize the lack of socio-political awareness of rights, as well as human dignity, results in trivialization of situations of injustice and oppression experienced by Brazilian society. And that social inequalities are problems that prevent Covid-19 from being faced. In the search for the place to speak of Mathematical Education in this scenario, we reinforce the Primordial Triangle of Ubiratan D'Ambrosio understood as: an individual, another individual and, therefore, society, and nature as a philosophical and methodological possibility of action. Allied to this, the formatting power of Skovsmose's society and the "read" and "write" of Gutstein's world represent a form of insertion of mathematics in the challenge of building a society that respects human dignity. Aware of this role, it is necessary that Mathematics Education recognizes its transforming potential, excelling in the formation of young people supported by the principles of humanization, sustainability and peace.
\end{abstract}

Keywords: Mathematics Education. Human dignity. Pandemic. Post-pandemic. Socio-political formation.

\title{
Apresentação
}

Em face ao contexto social contemporâneo marcado por intolerâncias, exclusões e, principalmente, por violações da dignidade humana acentuadas 
pelo cenário de pandemia da doença Covid-19, trazemos, neste texto, reflexões sobre o papel da Educação Matemática enquanto promotora dos direitos humanos e da cultura de respeito à dignidade humana. Utilizamos, como interlocutores, os pesquisadores D'Ambrosio (1996; 2005a; 2005b; 2013; 2018), Skovsmose $(2005 ; 2013 ;$ 2014; 2017) e Gutstein $(2006 ; 2016)$ para obter o lugar de fala da Educação Matemática no desafio de construir uma sociedade que preza a vida digna para todos.

Ora, ambicionar uma sociedade que preserva a dignidade humana em todas as suas nuances, é crer que a educação seja protagonista na construção de um processo formativo de estudantes capazes de trilharem sua trajetória com alteridade e dignidade, respeitando as diferenças e reconhecendo o 'outro'. Esse processo prima por transformar a sociedade. No entanto, sabemos não ser apenas a educação incumbida em tal enfrentamento; é preciso políticas públicas e ações efetivas do Estado e, sobretudo, de mobilizações dos movimentos sociais e da sociedade civil. A emblemática frase de Paulo Freire dá força para essa reflexão: "Se a educação sozinha não transforma a sociedade, sem ela tampouco a sociedade muda" (FREIRE, 2000, p. 31). Vejam como a educação é posta como protagonista na transformação da vida!

Assim também, a Educação Matemática deve se responsabilizar na formação para vida! Reconhecendo, no seio da sociedade, os problemas sociais e as violações dos direitos para utilizar de seus instrumentos na defesa da equidade, da justiça social e da vida digna. Como isso é possível? É o que pretendemos argumentar com este texto.

Se, para Moreira (2020b, p. 10), "a escola, como instituição social que é, é a grande responsável por realizar a mediação entre o indivíduo e a sociedade, que prepara o primeiro para enfrentar e contribuir para os problemas da segunda", para nós, a conjugação da teoria com a prática - o que, por si, demonstra grande capacidade de ajudar a conhecer a realidade educacional assentada em uma via de mão única, que não dá voz a todos os atores educacionais ali envolvidos - propicia condições ao professor de matemática planejar o resultado gerado por esse processo de mudança social e educacional a que almejamos, que é a prática social da matemática.

Não é fácil convencer que a matemática pode atingir dimensões além da cognição e da técnica, visto que ainda é considerada uma área "rígida, fria e austera", afirma D'Ambrosio (2013, p. 13). Apontar que ela caminha e permeia confortavelmente por diferentes áreas e dimensões, tais como: artes, filosofia, antropologia, história, política, ética e estética; bem como, fortemente, situa-se nas questões socioculturais e sociopolíticas da sociedade, muitas vezes é considerado por leigos, estudantes ou até por professores de matemática, como falácias utópicas. Mas "como ser educador sem uma utopia?", provoca D'Ambrosio (2005b, p. 105). 
Em consonância, Moreira (2020a, p. 14) traz a seguinte reflexão:"Se ela [matemática] pode flertar com os pensamentos educacionais, filosóficos, artísticos, políticos e, principalmente, com a promoção dos direitos humanos, ela é libertadora!" Para este caminho, organizamos o ensaio em três seções, além desta apresentação e das reflexões finais. Na primeira, apresentamos a concepção de dignidade humana que sustenta nossas reflexões. Na segunda seção, refletimos sobre a sociedade brasileira em tempo de pandemia. E por fim, na terceira seção, trazemos as contribuições da Educação Matemática para a promoção da cultura de respeito à dignidade humana.

\section{A dignidade humana como construção intersubjetiva}

A defesa da dignidade humana ocupa lugar central no discurso apregoado pela perspectiva emancipatória e intercultural dos direitos humanos proposto por Boaventura de Sousa Santos. O sociólogo faz severas críticas na concepção ocidental dos direitos humanos defendida nos principais tratados e declarações universais, assim como, identifica a "fragilidade dos direitos humanos enquanto gramática de dignidade humana" (SANTOS, 2014, p. 12).

Os direitos humanos, na concepção ocidental, representam uma linguagem hegemônica da dignidade, portanto, a grande maioria da população não é sujeito de direitos humanos, pois foi historicamente concebida para vigorar apenas o"lado de cá da linha abissal" (SANTOS, 2014, p. 17) e que, desse modo, tem produzido exclusões radicais. À vista disso e diante de um mundo cada vez mais plural e complexo, Santos (2014) propõe uma concepção contra-hegemônica baseada na linguagem de emancipação social e humana. Essa concepção busca a transformação social radical e progressista para a construção de uma sociedade mais justa e mais digna para todos,

\footnotetext{
Uma vez que todas as culturas tendem a distribuir pessoas e grupos de acordo com dois princípios concorrentes de pertença hierárquica e, portanto, com concepções concorrentes de igualdade e diferença, as pessoas e os grupos sociais têm o direito a ser iguais quando a diferença os inferioriza, e o direito a ser diferentes quando a igualdade os descaracteriza (SANTOS, 1997, p. 30).
}

Duas palavras podem expressar essa reflexão: diversidade e equidade. Isso, em nosso entendimento e diante do cenário atual, significa que é preciso reconhecer a diversidade do povo brasileiro em todas as suas pluralidades étnicas, raciais, sexuais, culturais, religiosas e, sobretudo, as pluralidades sociais. Além disso, expressa o direito de sermos diferentes na coexistência e de termos a igualdade de condições na sociedade, concomitantemente à liberdade 
de sermos o que somos.

Essa compreensão de direitos humanos substancia que todas as culturas têm versões diferentes de dignidade humana, uma vez que são incompletas e problemáticas nas suas concepções. Essa incompletude reforça a dinâmica dos direitos humanos e da sua construção intersubjetiva de dignidade humana.

Por outras palavras, Benevides (2005, p. 12) traz uma compreensão de dignidade humana semelhante a que é defendida por Santos (2014) e que faz interlocução com a nossa compreensão:

[...] dignidade é a qualidade própria da espécie humana que confere a todos e a cada um o direito à realização plena como ser em permanente inacabamento, à proteção de sua integridade física e psíquica, ao respeito a suas singularidades, ao respeito a certos bens e valores, em qualquer circunstância, mesmo quando não reconhecidos em leis e tratados. Dignidade é aquele valor - sem preço! - que está encarnado em todo ser humano. Direito que lhe confere o direito ao respeito e à segurança - contra a opressão, o medo e a necessidade - com todas as exigências que, na atual etapa da humanidade, são cruciais para sua constante humanização. Como ensina Kant: "as coisas têm preço; as pessoas, dignidade".

Destacamos que a dignidade humana, como a apresentada por Benevides (2005), considera o direito humano da realização plena, da proteção de sua integridade e do respeito a suas singularidades independentemente do reconhecimento dessa dignidade em leis e tratados. Conclui-se, deste modo, que a universalidade dos direitos humanos apresentada pelos tratados 'ocidentais' e fortemente rejeitada por Santos (2014), não representa e não caracteriza todos os povos e todas as culturas. Assim, não é possível falar em direitos humanos únicos, tão pouco em dignidade humana única, é preciso reconhecer a complexidade e a pluralidade do mundo contemporâneo, assim como as intersubjetividades que compõem a construção desses conceitos.

Sobre a vida digna, Santos (1997) nos instiga a refletir sobre a importância de não reduzirmos a realidade ao que existe, ao que está posto, porque, assim, seríamos obrigados a justificar o que existe, por mais injusto ou opressivo que seja. Interessante analisar essa afirmação e, ao mesmo tempo desolador, pois escancara o fato de naturalizarmos, por exemplo, as perdas dos direitos, as exclusões e, até mesmo, as barbáries que, ao nosso ver, foram potencializadas pela crise sanitária na qual estamos inseridos.

Presenciamos neste cenário, a conformidade do próprio oprimido ao ter seus direitos suprimidos, assim como ao sofrer diversos tipos de violências. Seguramente, a falta de consciência sociopolítica dos direitos e, especialmente, de dignidade humana, banalizam as situações de injustiças e de opressões vividas, por essa razão, é tão importante que a educação esteja comprometida em promover essa conscientização para que se possa transformar esta 
realidade em um lugar justo para todos.

\section{Sociedade brasileira e o cenário de pandemia}

O ano é 2020 e nele, experienciamos a crise sanitária mais intensa e de mais difícil prognóstico dos últimos tempos. O momento exige reflexões, visto que não será a última pandemia dada pelas projeções científicas; portanto, é substancial pensarmos no coletivo, na solidariedade e, essencialmente, no valor da vida humana.

Em meio à crise e diante de um país desigual como o nosso, é evidente que as misérias na sociedade se agravaram e, por esse motivo, é preciso construir pontes para o novo, praticar a empatia, reconhecer os direitos sociais e políticos, preservar a dignidade humana e enxergar o 'outro' para que, assim, possamos evitar o esvaziamento dos sentimentos e da humanidade que nos leva a banalizar as injustiças. Exige-se do Estado, mais do que em outros tempos, adotar uma postura de responsabilidade social e de criar legislações sanitárias emergenciais e permanentes, bem como políticas públicas sociais para que, nós, brasileiros, estejamos amparados pela política, pelo social, pela educação e pela ciência.

Nesse contexto, o coletivo sobressai o individual, não faz sentido acreditarmos nas expressões populares "salve-se quem puder" ou "cada um com os seus problemas", visto que, duramente, a crise sanitária tem evidenciado que não é este o caminho. Resgatando a icônica reflexão de Immanuel Kant, já lembrada neste texto por Benevides (2005, p. 12): "as coisas têm preço; as pessoas, dignidade". Mesmo que o Estado, junto aos donos do capital, esteja reforçando o contrário, o povo brasileiro chora pelas vidas perdidas pela Covid-19 e pelas desigualdades sociais que, há longas datas, vem massacrando o povo brasileiro. A gravidade se assenta de tal forma que, somente na educação, os dados pandêmicos são alarmantes e, segundo a Unesco (2020), 91\% do total de alunos do mundo e mais de $95 \%$ de estudantes da América Latina estão fora da escola devido à Covid-19 (MOREIRA, 2020b).

O fato é que a situação de crise sanitária nos deixou expostos, uma vez que foram escancarados os perversos abismos sociais do nosso país. Dessa maneira, a dignidade humana não está ameaçada por causa da pandemia, sempre esteve! A diferença é que agora enxergamos, com lupa, o nosso maior problema: a desigualdade social. Por isso, é complexo e problemático falar de dignidade humana quando temos imenso número de pessoas e grupos em situação de vulnerabilidade, que não têm sequer água potável, que precisam atravessar a cidade em transporte público para chegar ao trabalho, que moram em pequenos cômodos com inúmeros familiares ou que nem moradia 
têm. Sabemos que a lista das desigualdades é grande, mas estes são exemplos evidentes do quanto o problema é grave e desolador!

Se temos diversas realidades sociais e econômicas no Brasil, temos também diversas concepções de dignidade humana em tempo de pandemia. Para alguns, as discussões giram em torno de melhorar os serviços de delivery e da qualidade das aulas remotas da escola privada, para outros tantos, baseiam-se na melhoria do transporte público e para uma significativa parcela da sociedade, limita-se à busca por alimentação e por sobrevivência. Logo, a realidade que temos é que o vírus afeta desigualmente os desiguais! E que por isso, não sofremos apenas com a crise sanitária e econômica, mas também com a crise da democracia, da política, da educação e, tristemente, da humanidade.

A ciência, a política, a educação e a sociedade têm buscado formas de compreender e de combater a crise pandêmica por meio de ações a fim de amenizar as profundas perdas nos âmbitos, primeiramente, humano, por conseguinte, social, educacional e econômico do país, mesmo que essa não seja, necessariamente, a ordem de importância dada pelo Estado brasileiro. Aproveitando, é importante destacar que, em nossa reflexão, por motivo de foco, não entraremos no âmbito do descaso e das negligências do atual presidente da República Jair Messias Bolsonaro, contudo, manifestamos nosso entendimento em relação a sua falta de empatia, de solidariedade e de consciência humana frente a tantas mortes causadas pela Covid-19. Na mesma direção, ressaltamos "que é por meio da educação que se liberta um povo; para dizer que é preciso combater todo "talkey" com muita desconfiança e sabedoria" (MOREIRA, 2020a, p. 16), que objetiva, entre outros absurdos, deixar a população à própria sorte.

Seguindo com a reflexão sobre a busca por respostas e ações para o enfrentamento das crises vivenciadas, bem como de suas consequências, trazemos o seguinte questionamento: de que forma a Educação Matemática - sendo área de conhecimento que permeia a ciência e a sociedade e que, também atua na educação nas dimensões política e social - poderá contribuir para a construção de uma cultura de dignidade humana? Ou melhor, em que medida a Educação Matemática tem seu lugar de fala diante do atual cenário de crise sanitária e das violações da dignidade humana? Apresentamos, na seção seguinte, as aproximações teóricas para responder a esses questionamentos.

\section{Educação Matemática e suas contribuições para promo- ção da cultura de respeito à dignidade humana}

Além do cenário de pandemia, vivemos em uma sociedade cada dia mais violenta e excludente. Nela, acentua-se nas relações sociais, o medo, a ganância, o individualismo e o desrespeito aos direitos essenciais de uma vida 
digna. Mesmo diante dessa realidade, muitos professores julgam que sua ação educativa é politicamente neutra, sendo este, um equívoco ingênuo! Educar é um ato político! Por essa razão, a responsabilidade maior do professor vai além da sua disciplina específica (D'AMBROSIO, 1996). Com efeito, a dimensão política do educar abrange tantas outras ações em todo o processo educativo, tal como promover a cultura do respeito à dignidade humana.

Como dito, para obtermos o lugar de fala da Educação Matemática diante deste desafio, utilizamos as produções de Ubiratan D'Ambrosio, de Ole Skovsmose e de Eric Gutstein, considerados estimados pesquisadores da área. Para esses autores, a Educação Matemática deve ser crítica e, cada autor a sua maneira, apontam para a "fragilidade do estruturalismo pedagógico dominante" (D'AMBROSIO, 1996, p. 120). A exemplo, Skovsmose $(2013$, p. 21) considera que "os pressupostos do estruturalismo exemplificam uma negação quase que completa da Educação Crítica".

Isto impõe reconhecer que o indivíduo é um todo integral e, por esse motivo, não deve ser desvinculado do contexto histórico no qual o processo se dá, argumenta D'Ambrosio (1996) e continua:

A essência da minha proposta é uma educação universal, atingindo toda a população, proporcionando a todos o espaço adequado para o pleno desenvolvimento de criatividade desinibida, que ao mesmo tempo em que preserva a diversidade e elimina as inequidades, conduz a novas formas de relações intra e interculturais sobre as quais se estruturam novas relaçỗes sociais e uma nova organização planetária (p. 121).

A compreensão, portanto, de Educação Matemática dado por Ubiratan D'Ambrosio, busca a educação para "ética da diversidade", consistindo em respeito, solidariedade e cooperação. Para ele, a ética deveria pautar o comportamento de todos os professores (e indivíduos), pois conduziria à paz interior, à paz social, à paz ambiental e à paz militar. Vejam que a preocupação repousa na formação para além da racionalidade técnica e para além do “já desgastado ensino-aprendizagem baseado numa relação obsoleta de causa-efeito" (D'AMBROSIO, 1996, p. 121).

Defensor da Educação Matemática para a Paz, D'Ambrosio (2005a; 2005b; 2018) vê a importância de a matemática escolar focalizar suas ações em prol da melhoria da qualidade de vida e da dignidade humana como um todo e que a dignidade de cada indivíduo se manifesta no encontro com outros indivíduos. Nesse sentido, a paz interior diz respeito aos problemas e as dificuldades que enfrentamos no dia a dia, bem como ao relacionamento com o outro. A paz social é o estado que essas dificuldades não se apresentam, e a solidariedade com o próximo é essencial para atingi-la. A paz ambiental re- 
fere-se ao desenvolvimento e ao progresso de forma sustentável, tal qual a matemática não seja usada para a destruição na natureza. E como consequência, teremos a paz militar se todas as outras forem alcançadas. Por outras palavras, Skovsmose (2014, p. 31) fala da importância do aspecto político do ensino e da aprendizagem, visto que as "guerras e outras formas de violência na sociedade têm influência direta no modo como o "ir à escola" se estrutura entre a população". A responsabilidade social é destaque nesse aspecto e a Educação Matemática pode ser praticada nessa dimensão, para tanto, na raiz desse processo, está a possibilidade de a Educação Matemática causar impactos, não só educacionais, mas, também, de ordem social e política, bem como promover uma visão de mundo diferenciada em termos de justiça, paz, valores e coletividade.

Isso vem ao encontro do que Skovsmose (2013) chama do poder de formatação da matemática, ou seja, qual o papel da matemática na sociedade? Ela pode fazer intervenções na realidade? Diante disso, o autor argumenta:

\begin{abstract}
A matemática intervém na realidade ao criar uma "segunda natureza" ao nosso redor, oferecendo não apenas descriçỗes de fenômenos, mas também modelos para a alteração de comportamentos [...]. As estruturas matemáticas vêm a ter um papel na vida social tão fundamental quanto os das estruturas ideológicas na organização da realidade (SKOVSMOSE, 2013, p. 83).
\end{abstract}

A respeito da prática educativa nessa perspectiva, a Educação Matemática baseia-se na matemática que faz parte das práticas culturais dos estudantes, sempre levando em consideração a diversidade social, cultural e econômica, inclusive dos estudantes que pertencem às faixas marginalizadas da população (SKOVSMOSE, 2014).

O conceito de matemacia dado por Skovsmose (2017) trata-se do aspecto da responsabilidade social e da concepção de Educação Matemática para a cidadania, leitura e escrita do mundo com a matemática. Comparavelmente, para D'Ambrosio (2005a; 2005b; 2013) o termo materacia é capacidade crítica de inferir e propor hipóteses a partir de dados matemáticos, a preocupação vai além do contar e medir, pois propõe reflexões acerca dos seres humanos e da sociedade para compreender a realidade, significa assumir uma postura intelectual. Também nos estudos de Gutstein (2006), a leitura e a escrita com a matemática são referidas; "ler" tem o sentido de interpretar o mundo e "escrever" trata-se das formas de agir no mundo.

A abordagem de Gutstein para a concepção do papel da Educação Matemática está, em nossa interpretação, em consonância com a de D'Ambrosio e com a de Skovsmose. Pois Gutstein explica que sua tese em relação ao ensino e aprendizagem de matemática sustenta-se no fato de que "os estu- 
dantes precisam ser preparados através da educação matemática para investigar e criticar a injustiça, e para desafiar, em palavras e ações, atos e estruturas opressivas - isto significa "ler e escrever o mundo" com a matemática" (MOURA; FAUSTINO, 2017 p. 13).

\begin{abstract}
[...] os alunos desenvolvem uma consciência sociopolítica mais profunda através da aprendizagem e uso da matemática para estudar a realidade, que os prepara para moldar a sociedade usando a matemática, agora e no futuro. Os alunos passam a ver a matemática como útil nesse processo (uma mudança de disposição), reconhecem algumas de suas limitações e também aprendem que a matemática é apenas uma maneira de ler e escrever o mundo. Através da compreensão e atuação no mundo - mesmo que suas ações sejam limitadas por estarem na escola - eles também se transformam. (GUTSTEIN, 2016, p. 457, tradução nossa).
\end{abstract}

O desenvolvimento da consciência sociopolítica através da matemática é ponto chave defendida por Gutstein e, da mesma forma, a Educação Matemática Crítica "relaciona-se aos diferentes e possíveis papeis que ela poderia assumir em uma instância sociopolítica particular" (SKOVSMOSE, 2005, p. 136). Trata-se, por conseguinte, de reconhecer, por meio da matemática, os problemas sociais existentes, para tomar decisões baseadas na ética e atuar em sociedade de forma justa e digna, respeitando o outro e exercendo sua cidadania.

É importante destacar que, não se trata de uma cidadania submissa "na qual nossos estudantes aceitam regras e códigos que violam a dignidade humana" (D'AMBROSIO, 2013, p. 5). O cenário de pandemia, junto às desigualdades sociais alarmantes que vivenciamos e a cultura da violência e do ódio imposta pela polarização de classe, de gênero, de sexo, de raça, de cultura e, claro, pela polarização política, nos impõe pensarmos e aprendermos sobre como (sobre)viveremos a tudo isto com dignidade.

D'Ambrosio (2013), identifica três elementos fundamentais para que a vida se realize plenamente e com dignidade, nomeado por ele de Triângulo Primordial: um indivíduo, um outro indivíduo e, portanto, a sociedade, e a natureza. A eliminação de qualquer um desses três elementos, interrompe a vida e, para nós, minimamente, isso pode causar desastrosos danos a vida planetária, tal qual temos visto a partir do surgimento do implacável vírus SARS-CoV-2 e tantos outros males que já vivenciamos.

Em suma, não podemos mais educar ignorando as questões de sobrevivência da espécie! Muito menos deixar que apenas uma parcela de professores (áreas humanas) faça o trabalho de conscientização para vida. A matemática, seguramente, "é um instrumento poderoso para alcançar a justiça social, ou seja, o equilíbrio e a segurança, num mundo ameaçado pela exaustão de recursos, que leva à guerra e ao medo" (D'AMBROSIO, 2013, p. 
16). Vendo dessa forma, o propósito da ciência, da política e, evidentemente, da educação é focar na existência humana e na sobrevivência com vida digna para todos, respeitando a si mesmo, o outro e a natureza. Sem esse propósito, infelizmente, caminhamos para a direção errada!

Com isso, a Educação Matemática tem o papel de formar jovens que compreendam que é preciso ser solidários para viver no coletivo, que é preciso ter ética para atuar em sua profissão, que é preciso ter consciência sustentável para o bem viver e que é preciso reconhecer as diversidades para vivermos sem preconceitos. Trazemos, portanto, situações dadas pelos interlocutores do nosso referencial, para exemplificarmos como a matemática pode atuar nessa direção.

A respeito da desigualdade social no Brasil, Skovsmose (2017) traz a atividade matemática que aborda o Programa Social Bolsa Família. Diante da temática e dos instrumentos da matemática, esclarece-se, por exemplo, quanto dinheiro está envolvido no programa, quantas famílias recebem, quanto de imposto é gasto, qual percentual de aumento de renda de quem recebe, entre outros, de modo a realizar uma leitura mais completa do Programa, para depois tomar consciência do que ele realmente representa.

Na mesma direção, Gutstein desenvolve um trabalho em escolas públicas de Chicago de classe trabalhadora, ele utiliza a matemática para investigar questões de injustiça que são do interesse e do contexto social dos alunos, o que inclui racismo, violência, criminalização, predatórias práticas de empréstimos para a habitação, imigração, desenvolvimento imobiliário urbano - que exclui as famílias da classe trabalhadora (MOURA; FAUSTINO, 2017). Todas as atividades tendo como base a matemática como instrumetno de leitura e interpretação.

Como terceiro exemplo, será possível compreender o trinômio de $2^{\circ}$ grau e, ao mesmo tempo desenvolver a Educação Matemática para paz, para a ética e para os princípios da dignidade humana? Ubiratan D'Ambrosio (2005b) afirma que sim! Como possibilidade, ele apresenta o exemplo da trajetória de um projétil de canhão:

[...] aquele belíssimo instrumental matemático, que é o trinômio de $2^{\circ}$ grau, é o que dá a certos indivíduos - artilheiros profissionais, que foram, provavelmente, os melhores alunos de matemática da sua turma - a capacidade de dispararem uma bomba mortífera de um canhão para atingir uma população de seres humanos, de carne e osso, de emoções e desejos, e matá-los, destruir suas casas e templos, destruindo árvores e animais que estejam por perto, poluindo lagoas ou rios próximos. E ao voltar da missão, receber com tranquilidade elogios e condecorações. A mensagem implícita acaba sendo: aprenda bem o trinômio do $2^{\circ}$ grau e você terá a oportunidade de fazer tudo isso, pois somente quem for bem em Matemática terá suficiente base teórica para apontar canhões sobre populações (p. 106). 
Os exemplos são mostram o poder que a matemática tem de mudar mentalidades através da atividade crítica e com temas sociopolíticos. Já mencionamos que o mundo está ameaçado não somente pelas agressões ao meio ambiente e a natureza, mas, essencialmente, está ameaçado com o aumento das violações à dignidade humana, pois estamos com vidas humanas subordinadas ao medo, ao ódio e à violação dos princípios básicos sobre os quais repousa a civilização (D'AMBROSIO, 2018. p. 197).

A Educação Matemática, com vista em contribuir para a cultura de respeito à dignidade humana nas acepções teóricas de D'Ambrosio, Skovsmose e Gutstein, repousa na perspectiva que temos defendido de Educar em Direitos Humanos (VIEIRA; MOREIRA, 2018, 2020a, 2020b, 2020c), nessa ótica, tomamos os direitos humanos como "princípio educativo e como perspectiva educacional que atende aos anseios da formação pela dignidade humana e pela justiça social" (VIEIRA; MOREIRA, 2020a, p. 624).

Por fim, a partir das questões levantadas neste texto e das argumentações teóricas sobre o papel da Educação Matemática na promoção do respeito à dignidade humana, evidenciamos o quanto é importante a ressignificação dos propósitos da educação, especialmente, da Educação Matemática, uma vez que "a Matemática, uma das áreas nobres da Educação, é um direito universal!" (MOREIRA, 2020a, p. 16). É inconcebível e desumano, passarmos por tanta tristeza, por tantas perdas profundas e irrecuperáveis, para depois retornarmos à escola da mesma forma que antes.

Merece ser lembrado aqui o irlandês George Bernard Shaw, prêmio Nobel de Literatura de 1925, que assevera: "nós aprendemos da história que nós aprendemos nada da história". Ainda assim, preferimos crer na mudança e na inversão positiva do papel do professor e da educação, bem como crer que a pandemia sirva para refletirmos sobre o que temos 'ensinado' nas escolas e se esses 'ensinamentos' ainda valem a pena.

\section{Reflexões finais}

Hoje, mais do que em outras discussões de mudanças de paradigmas na educação, é imprescindível (re)pensarmos no papel da educação no pós-pandemia. Buscando argumentações sobre essa necessidade de mudança e sobre as possibilidades imensas da Educação Matemática em contribuir com esse contexto, iniciamos o texto com a concepção de dignidade humana como construção intersubjetiva.

Além disso, buscamos situar a sociedade brasileira no cenário de pandemia e que as misérias se agravaram diante desta crise sanitária. Em função disso, o momento exige práticas de empatia e solidariedade, sobretudo, da 
ação do Estado, da sociedade civil e dos educadores para garantir uma educação crítica e humana no pós-pandemia.

Em síntese, vimos que educar é um ato político e que abrange a formação em outras dimensões. Ressaltamos a promoção da consciência sociopolítica através da matemática, isto é, utilizar instrumentos da matemática para ler e interpretar o mundo, visando a atuação responsável na sociedade, baseado na ética, na sustentabilidade, na humanização e na paz.

No campo da Educação Matemática, citamos o Triângulo Primordial como possibilidade de equilíbrio e de construção de uma sociedade sustentável, ética, democrática e, antes de tudo, de vida digna. Esse triângulo é compreendido como um indivíduo, um outro indivíduo e, portanto, a sociedade, e a natureza. A não manutenção desses elementos, envolve o risco de sobrevivência da humanidade e da natureza.

A temática aqui tratada nos faz recordar os últimos escritos de Paulo Freire têm referência ao líder indígena da etnia pataxó-hã-hã-hãe Galdino Jesus dos Santos assassinado, em abril de 1997, por cinco jovens em Brasília que atearam fogo em seu corpo enquanto dormia. "Não é possível refazer este país, democratizá-lo, humanizá-lo, torná-lo sério, com adolescentes brincando de matar gente, ofendendo a vida, destruindo o sonho, in-viabilizando o amor" (FREIRE, 2000, p. 31). Este fato de 1997 é estarrecedor, mas sabemos, infelizmente, que não é uma violência isolada, dado que de lá para cá inúmeros episódios de barbárie têm ocorrido.

Esse contexto reforça ainda mais a necessidade de que é preciso "refletir sobre as incertezas que multiplicam-se na sociedade brasileira, principalmente porque as fake news ganham velocidade avassaladora, capaz de destruir sonhos e retroceder a democracia de nosso país ao seu embrião", e, então, "temos de superá-las e isso se faz com boa instrução, com matematização!" (MOREIRA, 2020a, p. 13).

Certamente, tão doloroso quanto a disseminação do vírus que nos aflige, é a disseminação do ódio contra indígenas, negros, pobres, mulheres, LGBTQIAP+ ${ }^{3}$, imigrantes, obesos, deficientes e tantos outros excluídos. De fato, os elementos do triângulo apresentado por Ubiratan D'Ambrosio fazem todo sentido nessa análise, o indivíduo, o outro e a natureza precisam coexistir harmoniosamente. Na falta de um, os outros não sobrevivem! Tão logo, é a inviabilização da vida digna e o do equilíbrio planetário!

Em suma, nas aproximações do lugar de fala da Educação Matemática diante deste cenário, reforçamos o Triângulo Primordial de Ubiratan D'Ambro-

3 Sigla que serve para se referir às pessoas que são (ou se identificam como) Lésbicas, Gays, Bi, Trans, Queer/Questionando, Intersexo, Assexuais/Arromânticas/Agênero, Pan/Poli, e mais. 
sio como possibilidade filosófica e metodológica de atuação. Aliado a isso, o poder de formatação da sociedade de Skovsmose e o "ler" e "escrever" o mundo de Gutstein representam uma forma de inserção da matemática no desafio de construir uma sociedade que respeita a dignidade humana. Ciente deste papel, é preciso que a Educação Matemática reconheça seu potencial transformador primando pela formação de jovens amparada pelos princípios da humanização, da sustentabilidade e da paz.

Na certeza disso, cabe recordar um trecho da música de Johnny Hooker que diz: "Um novo tempo há de vencer; Para que a gente possa florescer; E, baby, amar, amar sem temer; Eles não vão vencer". Quem ou o quê não vencerá? Para nós, será a ganância, o fundamentalismo, o conservadorismo, o preconceito, a violência, a guerra, a pobreza, a injustiça, o coronavírus, a corrupção, o capitalismo, o desmatamento, as fake news e tantos outros funestos "eles" que impedem nosso "florescer".

\section{Referências}

BENEVIDES, Maria Victoria. Prefácio. In: SCHILLING, Flávia (org.). Direitos humanos e educação: outras palavras, outras práticas. São Paulo: Cortez, 2005. p. 11-17.

D'AMBROSIO, Ubiratan. Educação Matemática: da teoria à prática. 3. ed. Campinas, SP: Papirus, 1996. (Coleção Perspectivas em Educação Matemática).

D'AMBROSIO, Ubiratan. Etnomatemática: elo entre as tradições e a modernidade. 2. ed. Belo Horizonte: Autêntica, 2005a. (Coleção Tendências em Educação Matemática).

D'AMBROSIO, Ubiratan. Sociedade, cultura, matemática e seu ensino. Educação e Pesquisa, São Paulo, v. 31, n. 1, p. 99-120, jan./abr. 2005b. Disponível em: https://www.scielo.br/pdf/ep/v31n1/a08v31n1.pdf. Acesso em: 20 jun. 2020.

D'AMBROSIO, Ubiratan. Um sentido mais amplo de ensino da matemática para a justiça social. In: I Congresso de Educación Matemática de América Central y el Caribe. Santo Domingo, República Dominicana, 2013.

D'AMBROSIO, Ubiratan. Etnomatemática, justiça social e sustentabilidade. Estudos Avançados, São Paulo, v. 32, n. 94, p. 189-204, set./dez. 2018. Disponível em: https://www.scielo.br/scielo.php?script=sci_arttext\&pi$d=$ S0103-40142018000300189. Acesso em: 20 jun. 2020. 
FREIRE, Paulo. Pedagogia da indignação: cartas pedagógicas e outros escritos. São Paulo: Editora UNESP, 2000.

GUTSTEIN, Eric. Reading and writing the world with mathematics: toward a pedagogy for social justice. New York, London: Routledge, Taylor \& Francis Group, 2006.

GUTSTEIN, Eric. "Our Issues, Our People-Math as Our Weapon": Critical mathematics in a Chicago neighborhood high school school. Journal for Research in Mathematics Education, Reston-VA, v. 47, n. 5, p. 454-504, nov. 2016. Disponível em: https://www.jstor.org/stable/10.5951/jresematheduc.47.5.0454. Acesso em: 20 jun. 2020.

MOURA, Amanda Queiroz; FAUSTINO, Ana Carolina. Eric Gutstein e a leitura e escrita do mundo com a matemática. Revista Paranaense de Educação Matemática, Campo Mourão-PR, v. 6, n.12, jul.-dez. 2017, p. 10-17. Disponível em: http://rpem.unespar.edu.br/index.php/rpem/article/viewArticle/1656. Acesso em: 20 jun. 2020.

MOREIRA, Geraldo Eustáquio. O Dzeta Investigações em Educação Matemática numa perspectiva de resistência e persistência. In: MOREIRA, G. E. Práticas de Ensino de Matemática em Cursos de Licenciatura em Pedagogia: oficinas como instrumentos de aprendizagem. São Paulo: Editora Livraria da Física, 2020a. p. 13-17.

MOREIRA, Geraldo Eustáquio. Do ensino presencial ao ensino remoto emergencial em função da Covid-19: apoios educacionais, sociais e tecnológicos para professores da rede pública de ensino do Distrito Federal. Universidade de Brasília: Edital COPEI-DPI/DEX No 01/2020, 2020b.

SANTOS, Boaventura de Sousa. Por uma concepção multicultural de direitos humanos. Revista Crítica de Ciências Sociais, Coimbra-PT, n. 48, jun. 1997. Disponível em: http://www.boaventuradesousasantos.pt/media/pdfs/Concepcao_multicultural_direitos_humanos_RCCS48.PDF. Acesso em: 20 jun. 2020.

SANTOS, Boaventura de Sousa. Se Deus fosse um ativista dos direitos humanos. 2. ed. São Paulo: Cortez, 2014.

SKOVSMOSE, Ole. Guetorização e globalização: um desafio para a Educação Matemática. Zetetike, Campinas, v. 13, n. 24, jul./dez. 2005. Disponível em: https://periodicos.sbu.unicamp.br/ojs/index.php/zetetike/article/ view/8646990. Acesso em: 20 jun. 2020. 
SKOVSMOSE, Ole. Educação matemática crítica: A questão da democracia. 6. ed. Campinas, SP: Papirus, 2013. (Coleção perspectiva em Educação Matemática).

SKOVSMOSE, Ole. Um convite à educação matemática crítica. 1. ed. Campinas-SP: Papirus, 2014. (Perspectivas em educação matemática).

SKOVSMOSE, Ole. O que poderia significar a educação matemática crítica para diferentes grupos de estudantes? Revista Paranaense de Educação Matemática, Campo Mourão-PR, v. 6, n. 12, jul./dez., p.18-37, 2017. Disponível em: http://www.fecilcam.br/revista/index.php/rpem/article/view/1562/pdf_231. Acesso em: 13 jun. 2020.

UNESCO. Global Monitoring of school closures caused by COVID-19. 2020. Disponível em: https://en.unesco.org/ themes/education-emergencies/coronavirus-school-closures. Acesso em: 13 jun. 2020.

VIEIRA, Lygianne Batista; MOREIRA, Geraldo Eustáquio. Direitos Humanos e Educação: o professor de Matemática como agente sociocultural e político. Revista de Educação Matemática, São Paulo, v. 15, n. 20, 2018. p. 548-564, set./dez., 2018. Disponível em: https://www.revistasbemsp.com.br/index. php/REMat-SP/article/view/174. Acesso em: 13 jun. 2020.

VIEIRA, Lygianne Batista; MOREIRA, Geraldo Eustáquio. O estudante imigrante e o papel do professor de Matemática como agente sociocultural e político. Dialogia, São Paulo, n. 34, p.185-199, jan./abr. 2020a. Disponível em: https://periodicos.uninove.br/index.php?journal=dialogia\&page=article\&op=view\&path[]=16711. Acesso em: 14 jun. 2020.

VIEIRA, Lygianne Batista; MOREIRA, Geraldo Eustáquio. Políticas Públicas no âmbito da Educação em Direitos Humanos: conexões com a Educação Matemática. Revista da Rede Amazônica de Educação em Ciências e Matemática, Cuiabá-MT, v. 8, n. 2, p. 622-647, maio/ago. 2020b. Disponível em: http://periodicoscientificos. ufmt.br/ojs/index.php/reamec/article/view/10500. Acesso em: 14 jun. 2020.

VIEIRA, Lygianne Batista; MOREIRA, Geraldo Eustáquio. Sociedade Contemporânea e o Ensino de Matemática: Conexões com a Educação em Direitos Humanos. Revista Brazilian Applied Science Review, Curitiba, v. 4, n. 2, p. 478490, 2020c. Disponível em: https://www.brazilianjournals.com/index.php/ BASR/article/view/7872/7426. Acesso em: 20 jun. 2020. 